\title{
Progress of Steelmaking Techniques and Modernization of Integrated Steelworks in Japan*
}

\section{By Ryuma HIRATA**}

\section{Postwar Development of the Japanese Steel Industry}

\section{General Review}

The postwar development of the Japanese steel industry may be discussed in three stages of ten years each; i.e., 1945 to 1954,1955 to 1964 , and 1965 to 1974. During the first decade, from 1945 to 1954 , the whole nation devoted itself to the breakaway from the war-devasted condition and restoration to the prewar level. The steel industry was not an exception. In the later half of this period, the industry directed increasing attention to the new techniques and high technical levels of several foreign countries, and the desire to introduce them became very keen. Subsequently some techniques in the fields of steelmaking and hot-strip and cold-strip production were imported.

\section{The 2nd Decade (1955 1964) - The Period of Pre- paration for Future Progress}

On entering the second decade, many steel companies threw much energy into the introduction of new techniques. Among the typical imported techniques were know-how on strip mill, plate mill, topblown converter and various operational aspects. The fact that such know-how was put into practical use earlier in Japan than in other countries contributed a great deal to the subsequent development of the Japanese steel industry. One of the major characteristics of this period was the use of high-purity oxygen which became available in large quantities through commercial production. Its use in the blast furnace and the basic oxygen furnace resulted in stable plant operation and marked increase in output, which, in turn, offered the basis for high-efficiency production. Especially, the oxygen top-blown converters came into popular use at a very rapid rate. Many new plants incorporating this type of converter were built to replace open-hearth furnaces. In 1965, eight years after the first converter of this type started commercial production in Japan, steel produced by this process accounted for $50 \%$ of the overall crude steel production. Many other new techniques, including computer control, adopted in individual processes of different fields of steelmaking brought about various improvements in product quality and production efficiency.

During this decade, basic knowledge which allowed an enormous leap in the subsequent period was accumulated, by actively introducing and digesting many new techniques from abroad. It was about this time that the Japanese steel industry caught up with the front-running United States. This was achieved by the positiveness of the enterprise leaders and the full display of the abilities of the excellent engineers and the highly trained workers.

\section{The 3rd Decade (1965 1974) — The Golden Period}

In the third decade, when the potential of steelmaking techniques rose so high, new steelworks were constructed in succession to meet the ever-increasing demands.

As distinct from those constructed during the preceding decade, the steelworks of this period were designed to achieve an annual production of $10000000 \mathrm{t}$ or more. High-efficiency steelworks of entirely new type appeared, as a result of not only the further expansion of but also the integrated combination of various techniques that had theretofore been developed individually. As a result, production of crude steel increased swiftly, and then came the golden period of of the Japanese steel industry. In the meantime, many of the costs involved in steelmaking, such as personnel expenses and raw materials cost, rose sharply, especially in the last few years of the period. However, such increases in production cost were overcome, helped by the high productivity and the increase in demand for steel products. (Fig. 1.) This is one of the major contributions that the industry has made to the country.

Conventional techniques came to be applied on larger scales, and many domestic techniques were developed. In the previous period, most of steelmaking equipment had been designed and manufactured by domestic plant manufacturers who obtained licenses from the United States and advanced European countries. Now it became possible to manufacture equipment using domestic techniques through the cooperation of the domestic plant manufacturers and the steel companies. Primary mills and continuous casting machines exemplify such domestic achievements. Some of them did not reach the level of the foreign counterparts, but they may be considered as a harbinger of the new era to follow, since they proved that steelmaking plant could be constructed without depending on foreign techniques. Further, with the lapse of time, more and more Japanese techniques came to be exported abroad.

* Based on the Special Lecture delivered by Mr. R. Hirata in commemoration of his winning Watanabe Gisuke Prize at the 89th ISIJ Meeting, April, 1975, at The University of Tokyo, Bunkyo-ku, Tokyo.

** Adviser, Nippon Steel Corp., Otemachi Chiyoda-ku, Tokyo 100. 


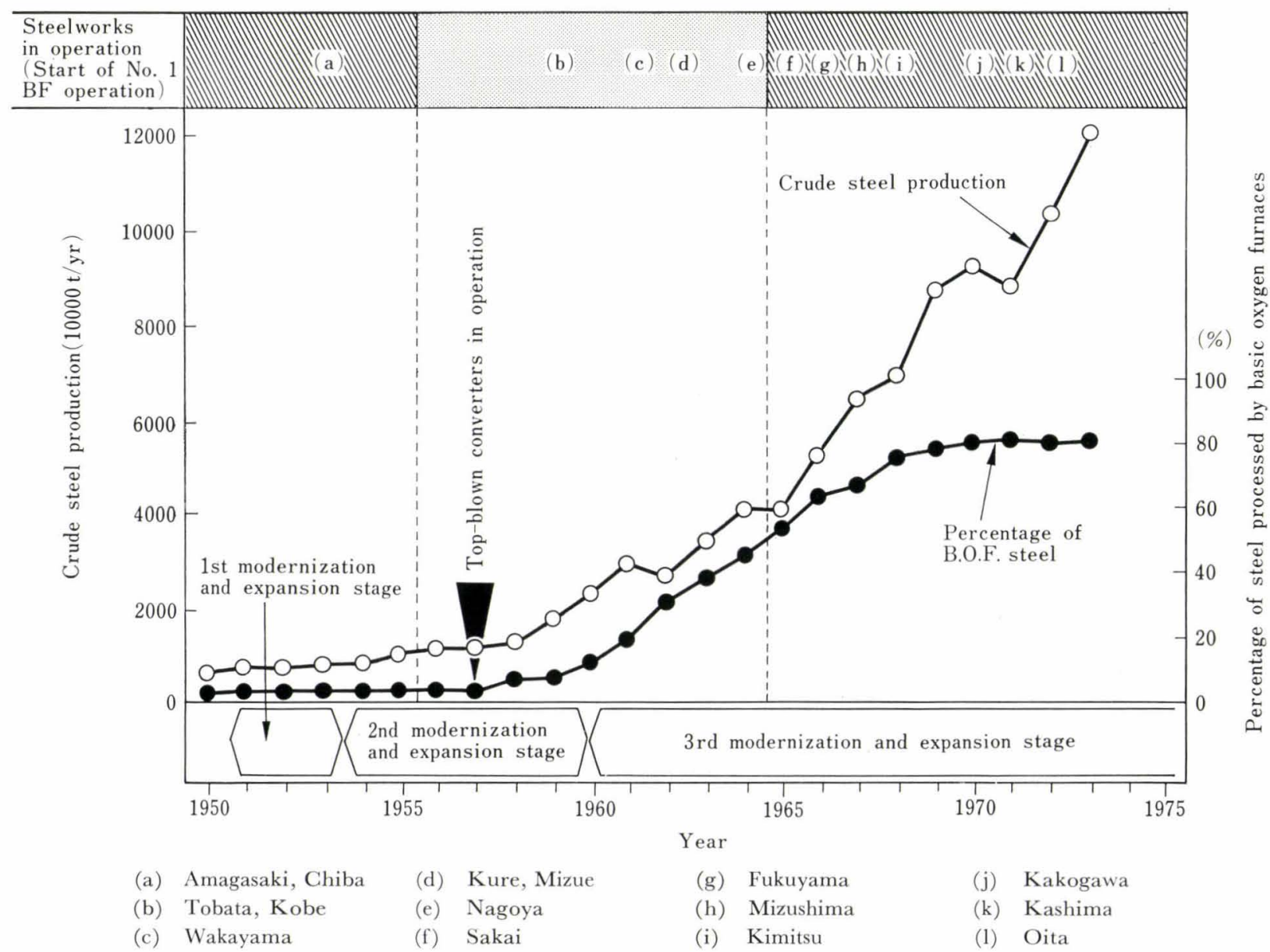

Fig. 1. Progress of crude steel production and the start of new steelworks

\section{Problems of the Present Decade (1975 1984)}

Following the above-mentioned rapid, extensive development, the Japanese steel industry this year entered the fourth decade after the war. Heavily influenced by the oil crisis continuing since 1974, the industry is now confronted with several difficult problems. But effective solutions as were found for each stage of the past twenty years have yet to be discovered.

Development and application of new steelmaking techniques, export of technical know-how to foreign countries, replacement of existing mills with thoroughly rationalized ones embodying the best of modern technology, and so on are being proposed. But no definite way in which to proceed has been decided.

It is keenly felt that suitable guidelines should be set down as soon as possible by calling on the expertise of the entire industry. And, once decided, these guidelines must be put into action, whatever technical innovations may be required.

\section{Adoption of Modern Techniques at New Steel- works}

\section{Summary}

Oita Works of Nippon Steel Corporation was constructed as a modern works embodying the latest steelmaking techniques. The following paragraphs will describe how various problems were encountered and solved in the course of its construction.

Fuji Iron and Steel Co., Ltd., a predecessor company to Nippon Steel Corporation, and Oita Prefecture concluded an agreement in 1961 to construct Oita Works in accordance with the latter's Industrial Plant Invitation Policy, which was immediately followed by land reclamation and leveling work. For some reasons, however, construction of the Works was not started until 1969. But this delay proved favorable to the company from the technical viewpoint, because it permitted full use of new techniques developed rapidly during that time, and to prepare for further technological progress in the future.

\section{Technical Requisites for the Works}

In carrying out the construction project of this new steelworks, the basic concept had to be established first. To this end, the following four factors were selected as the major design considerations:

First, the Works was to be sized to accomplish annual production of $10000000 \mathrm{t}$ or more, in terms of crude steel, at the time of its completion. This created not much dispute since it was then generally accepted in the industry that construction of the largest practicable works yielded the greatest possible merits from mass production.

Second, the Works was to be designed to remain immune to inevitable future increase in various costs, as otherwise its profitability would be impaired. 
With regard to labor cost, reduction of plant personnel through the adoption of extensive labor-saving equipment, rationalization of transportation systems -incidentally, the steel industry is often linkened to the transportation industry - and design of integrated, high-efficiency processes permitting effective utilization of raw materials, fuels and other supplies were contemplated.

But it was clear that these objectives would not be achieved by the extension of conventional techniques. What was needed was a drastic turn from old ideas to new ones.

Third, a number of anti-pollution measures were designed. The conditions of the original agreement concluded in 1961 were reviewed, and a new agreement was signed to provide the Works with as much pollution control equipment as possible in accordance with the requirements of laws and regulations, in order to protect the regional community. This agreement also confirmed the company's attitude to carry out extensive investigations and to reflect the findings on the design of such equipment.

Fourth, a total information processing system covering the entire works was to be introduced to efficiently and accurately handle a huge amount of data that were expected to become more and more diversified. Partial computerization would not be enough.

\section{Basic Construction Concept}

\section{Evaluation of Technical Potentiality}

As described above, it became the basic object of the project to satisfy all requirements set out for the Works by active adoption of new techniques, so that it should not grow obsolete for a long time after starting its operation. For this purpose, the following technical checkups were made.

For the first stage in which only one blast furnace was to be operated, a blast furnace producing $10000 \mathrm{t}$ of pig iron a day, two 300-t capacity basic oxygen furnaces, monthly production of $300000 \mathrm{t}$ and 270000 $\mathrm{t}$ of slabs and hot-strips, respectively, were selected as design conditions. To meet these conditions, the blast furnace must have a volume of $4000 \mathrm{~m}^{3}$ or more, the largest one operating then was of the $3000 \mathrm{~m}^{3}$ class. Conventionally, the volume of blast furnace had been increased by about $500 \mathrm{~m}^{3}$ at a time. So an increase of $1000 \mathrm{~m}^{3}$ envisaged for this project involved several technical difficulties. (Fig. 2)

The technical possibility of operating such a huge blast furnace efficiently and stably was studied in all aspects of equipment and operation. It was found that such operation would be possible if stave cooling, ultra-high-pressure operation under 2.5 atmospheric pressures, extensive instrumentation, and an effective computer control system were adopted.

Rationalization of transportation was one of the most important points in the design of basic layout. In order to form a simplified transportation system that eliminates overlapped transport and shifting of cargoes to the greatest possible extent, the concept of on-line processing was planned to be introduced into any applicable system of cargo handling. But it be-

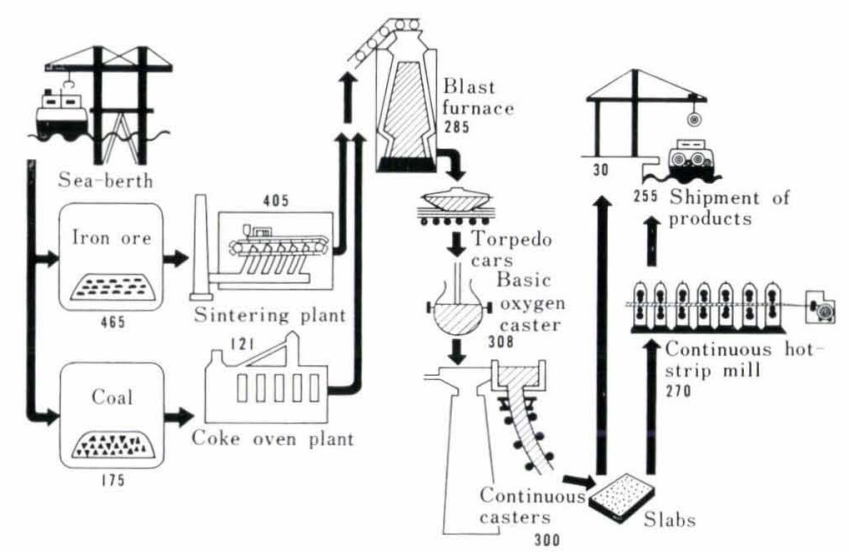

At the one blast furnace stage

At the $1000 \mathrm{t} /$ month stage

Fig. 2. Production flow and balance of Oita Works

came clear that it would cause a loss of flexibility, which, in turn, would lower the ability of the system to cope with fluctuations under various conditions. Then, further study was made to make up for this contradiction, which led to the following idea that necessitated continuous, computer-controlled transportation of cargoes packed into larger units so as to decrease their number.

The idea essentially comprised provision of a seaberth that permits receipt of raw materials from large vessels, 600-t torpedo cars carrying larger quantities of hot metal, a conveyor belt network and its control system that allows simplification of cargo flows, elimination of the primary-mill process and simplification of slab flows by the adoption of the continuous casting process, minimization of a railway network, apporpriate arrangement of yards with buffering functions and automation of their control.

Technically, they involved many unknown factors, and construction of the sea-berth and the continuous casting mill were of particular importance. They will be discussed in some detail later.

A total computer system for the communication and control of information serves as a "nervous system " that organically coordinates individual production processes in the works. But such systems had conventionally been utilized only partially within certain limits, although much discussion had been made to use them more extensively for applications of greater importance. Such limited use of computer systems may be accounted for by the facts that they had not been so reliable in operation, and that they had not been incorporated in old steelworks, when they were initially constructed. But the trend of those days indicated that it would be much regretted in the future if we did not totally computerize the Works. So the design was started, employing the total expertise of the computer system planning staff of the company.

\section{Establishment of Five Design Objectives}

By taking into consideration all the requirements and the results of the technical studies and evaluations discussed above, the following five basic objectives were established for the concrete design of this new works: 
(1) Construction of a large sea-berth that would permit receiving raw materials from large ore carriers, with a view to cutting down transportation cost, since the Works was to depend mostly on foreign countries for the supply of raw materials, including iron ore and coal, as other Japanese steelworks do. (Photo. 1)

(2) Introduction of large-sized, high-efficiency, new designs for such major equipment as blast furnaces, basic oxygen furnaces, continuous casting machines and continuous hot-strip mills and such auxiliary equipment as power- and oxygen-supply facilities. (Photo. 2)

(3) Adoption of continuous casting machines that would insure marked improvements in production yield and unit consumption of raw materials and utilities, rationalization of transportation, and saving of manpower and energy through the elimination of the primary mill stage. (Photo. 3)

(4) Setup of a high-grade total computer system (Fig. 3) that would be able to efficiently and accurately handle, with only a few operators, a large number of problems that were expected to grow more and more complicated and diversified.

(5) Provision of environment protection measures, including afforestation inside and outside the Works, intended not only for mere prevention of environmental pollution, but also for creation of better regional environment, in order to strengthen co-existence with the surrounding community. Special consideration was given to that point in designing the layout of the Works (Fig. 4).

Following such preparatory steps, construction of the Works was started. They following describes how the technical studies and decisions were made, by way of example, in the case of the sea-berth and the continuous casting process.

\section{The Processes of Technical Decisions \\ 1. Construction of a Sea-berth}

(1) Preference for a Sea-berth

The annual production capacity of Oita Works set forth in the original plan of 1961 was $4000000 \mathrm{t}$. But it was increased to $10000000 \mathrm{t}$ or more in 1969 when construction work was actually started. The site initially prepared for the Works became insufficient, but there was available only extremely limited space for expansion. Therefore, the layout of the entire works had to be designed with the utmost care.

In the meantime, a depth of $30 \mathrm{~m}$, indispensable for receiving imported raw materials from large ore carriers, was obtainable, without dredging, at a point $400 \mathrm{~m}$ off the reclaimed land. Then, it was considered that a pier having no breakwater would be best suited for making the best use of this advantage of Beppu Bay.

The needs to achieve effective utilization of the limited space and to accommodate large vessels of $250000 \mathrm{t}$ or more deadweight capacity, in combination, resulted in the selection of a sea-berth system.

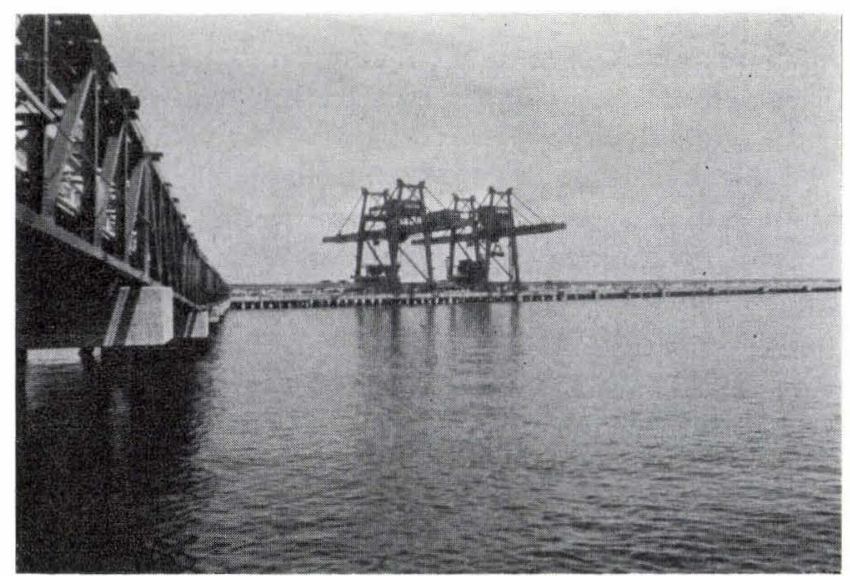

Photo. 1. The sea-berth of Oita Works

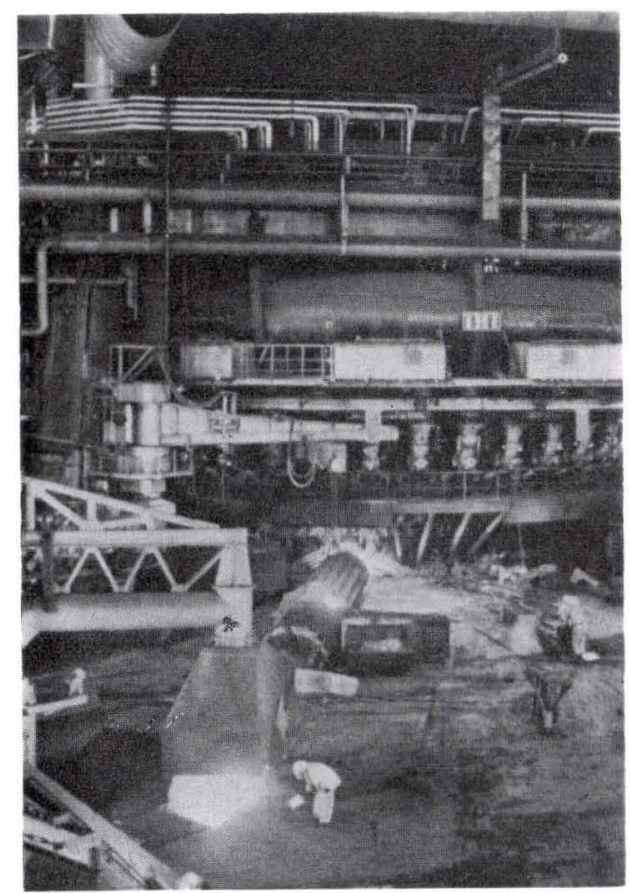

Photo. 2. Tapping of pig iron from the blast furnace

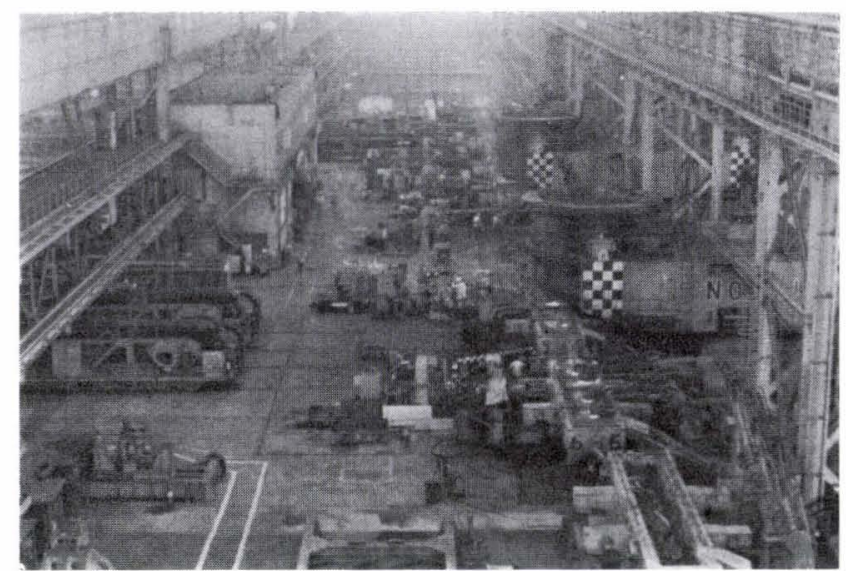

Photo. 3. The continuous casting machines in operation

(2) Comparison between a Sea-berth and a Wharf within a Breakwater

Conventional raw materials receiving facilities had been provided on a wharf built on the shore and sur- 


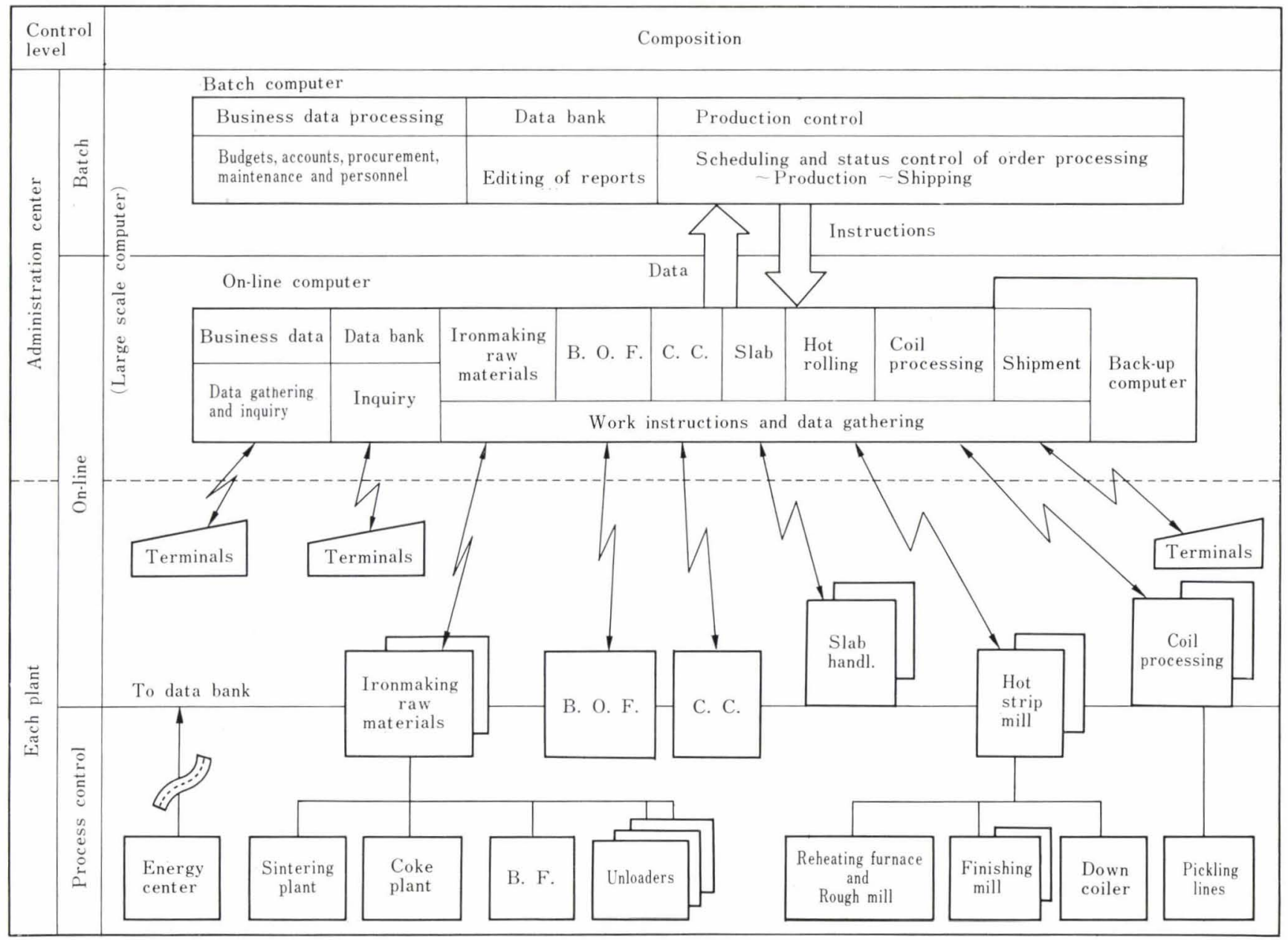

Fig. 3. Make-up of the computer system

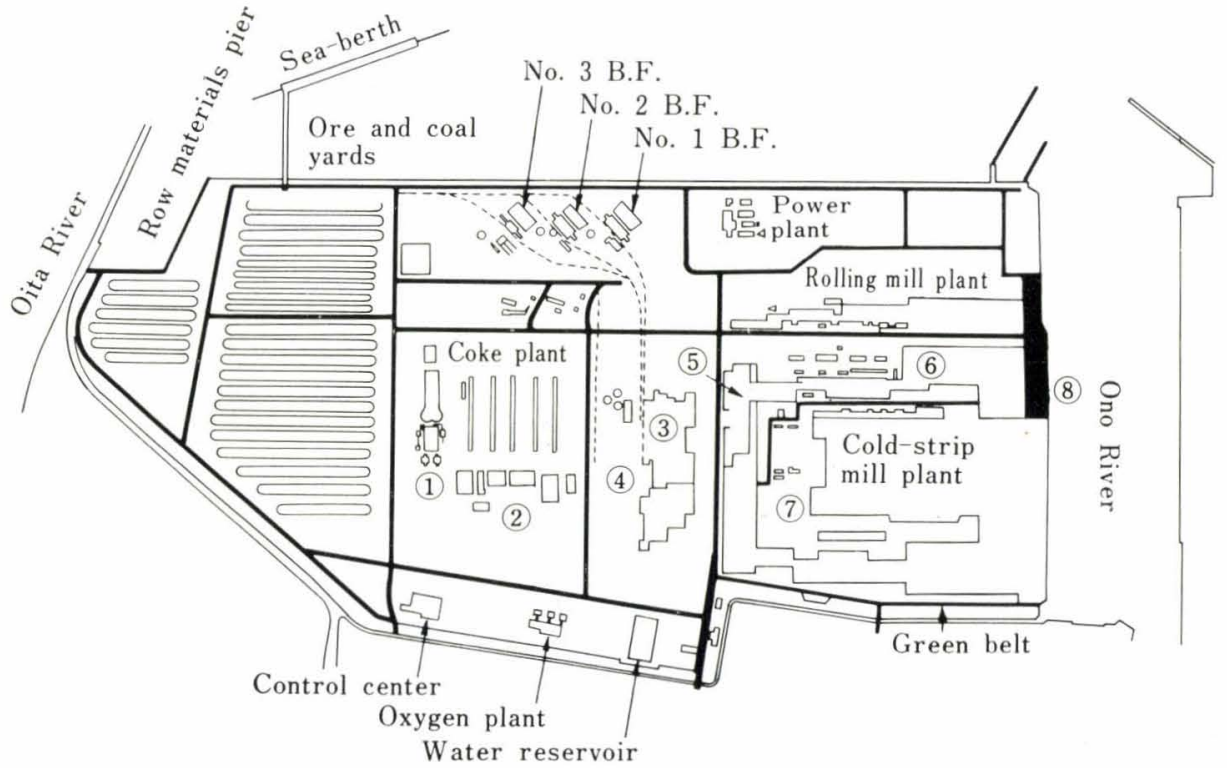

(1) Sintering plant

(2) Chemical by-product plant

(3) No. 1 continuous-casting plant

(4) No. 2 continuous-casting plant

(5) Slab yard

(6) Hot-strip mill plant

(7) Laboratories

(8) Product shipment pier

Fig. 4. Layout of Oita Works

rounded by a breakwater. In contrast, the sea-berth planned for this project consisted of a pier mounted with unloading facilities. This pier was designed so that waves could pass below, therefore mooring of vessels was considered to be relatively easy even without a breakwater.
A rough comparison of the two methods indicated that the sea-berth would be more advantageous in respect of vessel maneuverability, selection of suitable location, effective use of plant premises, possibility of future expansion, and construction of a $30 \mathrm{~m}$ deep mooring structure. There were some problems, too. 
One of them was that it would be more susceptible to the influence of weather conditions. Also, a doubt was raised as to whether such a structure on the sea could remain reliable for a long period of time.

Various data on weather conditions of the area were examined, including occurrence of winds of velocity of $10 \mathrm{~m} / \mathrm{sec}$ or more, and their seasonal direction. It was found that the wind blew mostly from the northwest throughout the year, and it grew stronger in winter. According to the statistics of the past 51 years, typhoons hit the area 103 times, or twice a year on the average. Further, it became clear that "Taiwan Bozu", the atmospheric depression developing near Taiwan in the East China Sea, visited the area toward the end of winter, especially in February. On such occasions, the sea-berth would become unusable for two to four days at a time. But it would be the same with a wharf surrounded by a breakwater.

It was further confirmed that the distance over which the waves would be carried by a strong northwest wind was 10 to $15 \mathrm{~km}$ at the most, owing to the favorable geographic condition of Beppu Bay. All in all, these investigations on winds and waves indicated that the sea-berth would have an operation rate of $90 \%$ even in the worst month, being not in the least inferior to a wharf and breakwater from the weather aspect.

\section{(3) Design of the Sea-berth}

This sea-berth carrying heavy, massive unloading facilities was to be constructed in the sea at a point $30 \mathrm{~m}$ deep, using 80 to $90 \mathrm{~m}$ long steel pipe piles. This rather excessive length was necessary because the firm stratum that could carry the pile load was found to lie at a considerable depth. So its safety was checked up from various aspects as discussed below.

The first problem related to earthquake resistance. It was studied by employing the "Modified Seismic Intensity System Allowing for Responses " which was being developed in those days, instead of the conventional static seismic intensity system. Records of earthquakes that had occurred in the neighborhood of Oita were carefully investigated. In connection with such information natural vibration period, damping factors, etc., of structures, of which no records were available, forced vibration tests were performed of existing structures. This sea-berth was expected to have a unique, top-heavy structure, carrying huge unloading facilities above 80 to $90 \mathrm{~m}$ long steel pipe piles. So, for the sake of accuracy, vibration tests using a 1/100 scale acrylic resin model were effected, in addition to ordinary structural calculations. (Figs. 5 and 6, Photo. 4)

The second problem was that of designing the long steel pipe piles. According to their arrangement plan designed with consideration for economy and work efficiency, each pile was thought to be subjected to a load of 300 to $500 \mathrm{t}$. However, no piles had been used for such heavy-loaded applications, and, therefore, much discussion arose as to their workability and the limit of their bearing force. Theoretically, it was not certain if the driving force of a hammer

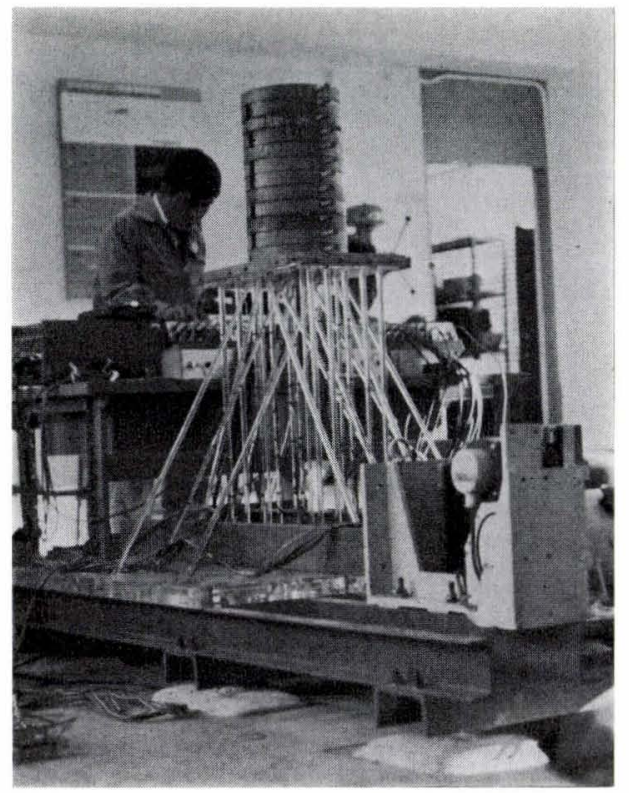

Photo. 4. Oscillation test with a $1 / 100$ scale acrylic resin model of the sea-berth

of the largest class then available in the world would reach the opposite end of the pile, and, therefore, if the expected bearing force could be obtained. To clear up such uncertainties, driving tests were performed under the same conditions that were thought to prevail in the actual project site. Also, 1200 -t load tests and 900-t pull-out tests were made by using part of the actual sea-berth structure constructed. All of these tests performed on the sea were unprecedentedly large in scale.

The third problem met was in the assurance of the soundness of the welded portions in the longlength piles. The maximum length manufacturable in the shop was about $15 \mathrm{~m}$, which necessitated welding together six to seven unit pipes to obtain a pile 80 to $90 \mathrm{~m}$ in total length. Because of the nature of their application, the pipes had to be welded together with enough strength, and properly aligned throughout. In order to meet these requirements, welding to make long-length piles was done on land where the work could be performed with greater ease, with the exception of batter piles exceeding $90 \mathrm{~m}$ in length which included one field welding, on the sea, per piece because of the limit of the welding machine's capacity. Such batter piles were welded by the semiautomatic method which had never been employed for any similar purpose, and all of the welded pieces were subjected to X-ray inspection, thereby increasing the efficiency of the work and insuring the desired quality of the piles.

The fourth problem was concerned with structural analysis. The sea-berth had to be analyzed as a cubic structure made up of structural steel piles that would undergo elastic deformation. Therefore, a block, $45 \mathrm{~m}$ wide and $95 \mathrm{~m}$ long, consisting of about 100 steel piles was analyzed under all conceivable load conditions, using a large computer. By this means, design programs for the individual members were de- 


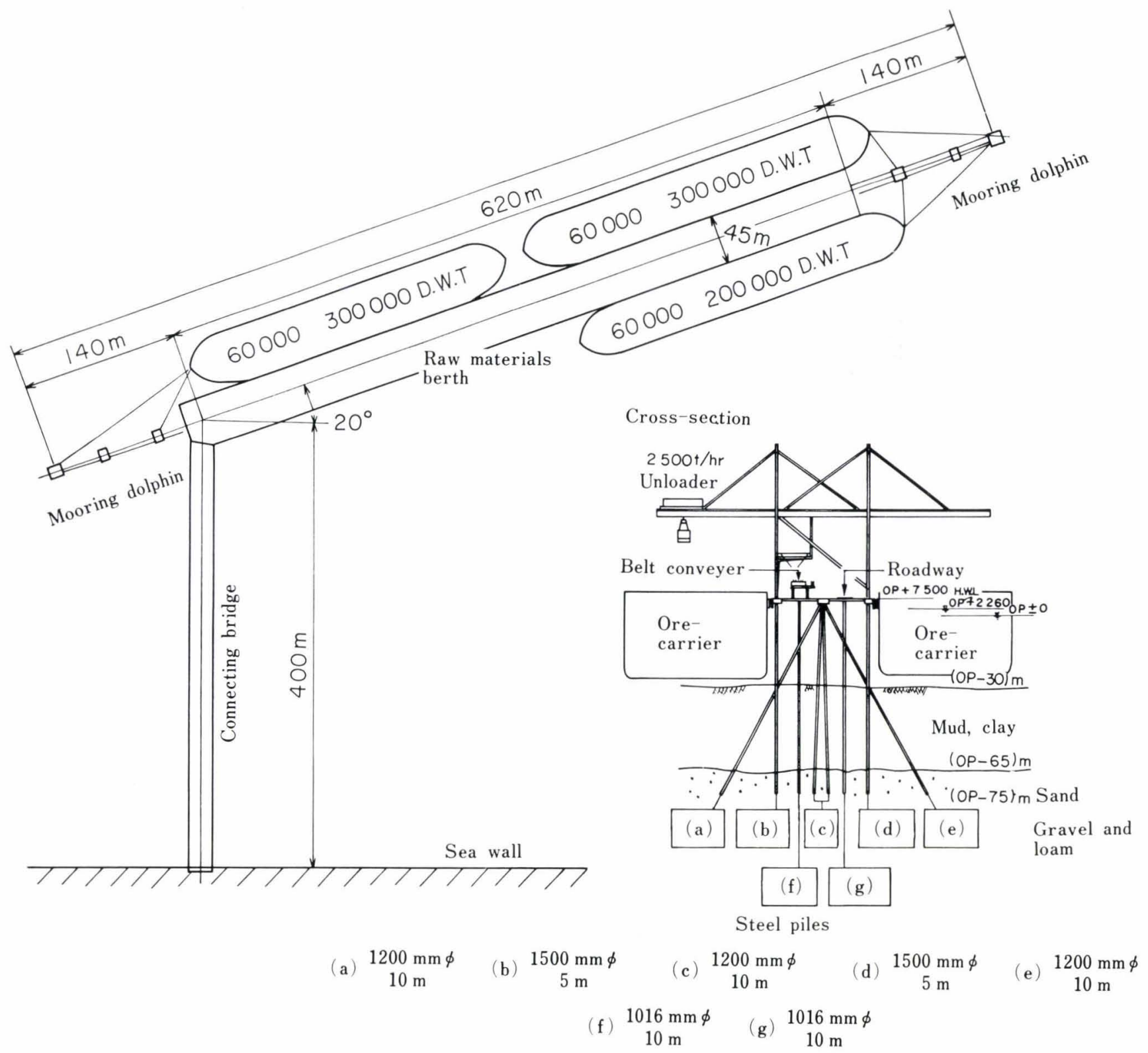

Fig. 5. Overall plan and cross-section of the main raw materials berth

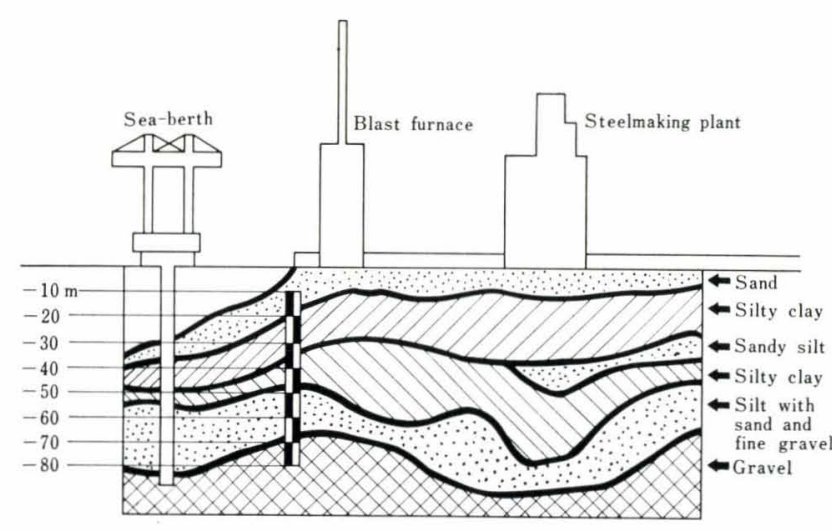

Fig. 6. Geological cross-section

veloped.

The fifth problem was concerned with the prevention of corrosion of the steel pipe piles. As a result of various studies, it was decided to make the wall thickness of the pipes $2 \mathrm{~mm}$ greater than the values calculated according to other requirements, in order to provide a corrosion allowance. Also, for preventing the occurrence of corrosion itself, an aluminum anode was fitted to the submerged portion of every pile. On the other hand, those portions of the piles which stand well above water and the lower splash zone were coated with special paint.

Based on these basic design studies, the facilities to receive raw materials for Oita Works designed to achieve an annual production of some $10000000 \mathrm{t}$ were completed, using approximately $37000 \mathrm{t}$ of structural steels. Among such steels were included about 740 steel pipe piles whose maximum diameter and length were $1500 \mathrm{~mm}$ and $92 \mathrm{~m}$, respectively.

2. Adoption of Full Gontinuous Casting Process

(1) Recognition of the Potentialities of the Process

The idea of casting molten steel continuously seemed to offer us a variety of technical possibilities in the furture. This method would permit combining the ingot-making, soaking, and primary-mill stages 
stages into a single process. We thought we would be able to take great strides toward the end invariably pursued by the modern steelworks if we adopted the full continuous casting process. The advantages we expected to enjoy were as follows.

1) Rationalization of plant layout:

Effective use of limited land (The essential requisite of Oita Works)

Simplification of material and product flows

2) Saving of labor through process simplification:

Saving of 100 or more operators with a continuous casting plant of 4000000 -annual-ton production capacity

3) Improvements in quality:

Improvements in surface conditions, uniformity of properties, etc.

4) Promotion of energy saving:

Saving by $30 \%$ in the steelmaking process

5) Saving of raw materials:

An improvement of 5 to $10 \%$ in the overall production yield

6) Creation of clean working environments:

\section{Automation of equipment}

The rationalization of the plant layout under item (1) would permit effective utilization of the limited land, the need for which was keenly felt especially with Oita Works, simplification of materials and products flow, resultant rationalization of transportation systems, and ready introduction of computer control.

The improvements in product qualities under item (3) would be possible since the continuous casting process would not be influenced by the splashing of metal, mold conditions, or other factors, as was the case with the ingot-making process. Especially marked improvements could be expected in the surface condition of the continuous cast products. Also, more uniform internal properties would be obtained, compared with the rimmed and semi-killed steels.

The saving of energy under item (4) would be chiefly by the elimination of the soaking pits necessary for the primary mill, and also by the remarkable improvement in the production yield of the entire steelmaking process, expressed in the ratio of iron ore charged to slabs produced and conditioned. About $30 \%$ of the energy was expected to be saved in the steelmaking process (from melting to slab conditioning).

The creation of clean working environments under item (6) had been difficult, largely owing to the ingotmaking operation which generated much dust and heat. But the continuous casting method would achieve it with ease as it involved few factors that would impair the working environment. Besides, this method, highly mechanized and automated, was expected to decrease the labor load to the minimum.

(2) Problems Encountered

Despite such advantages, however, the continuous casting method was not yet in popular use. It was not without reason. In 1969 or thereabout when construction of Oita Works was going to be started, the continuous casting method was still in its infancy. For instance, Nippon Steel at that time was operating only one bloom-slab caster of Japanese make, and was constructing wide casters in two works. The entire amount of steel treated by this method in Japan accounted for only about 5\% of crude steel production. The general situation was almost the same in the United States, too. It was the almost unanimously accepted opinion of the day that the ingot and primary mill process would be supplanted by the continuous casting process in the future. But not a few people remained negative as to the possibility of utterly eradicating the primary mill and depending totally on the full continuous casting method, because there were still many difficulties to be overcome.

The following are the problems we had to solve before deciding on the adoption of the continuouscasting method.

First, there was a doubt about the productivity of continuous casters; namely, as to whether they could operate keeping pace with the highly productive large blast furnaces and basic oxygen furnaces. The best 2-strand wide slab caster available in the world at that time could produce only $100 \mathrm{t} / \mathrm{hr}$, or 50000 to $60000 \mathrm{t}$ monthly. This was not only far short of the $600 \mathrm{t} / \mathrm{hr}$ produced by the 300-t basic oxygen furnace, but also inferior in efficiency and operation rate to the primary mill having a production rate of $550 \mathrm{t} / \mathrm{hr}$ or so.

Second, there were too many limitations in respect of production process, size, lot and type of steel, so that it was doubted whether the aimed annual production of $10000000 \mathrm{t}$ or more could be achieved.

Third, there were many problems to be solved with regard to manufacturing technique and process economics since steel of the quality corresponding to the conventional rimmed steel was required. In this connection, there were three continuous casting principles in those days: (1) the substitution of aluminum killed steel proposed by Mannesmann A.G., West Germany, etc., (2) the rimmed continuous casting method proposed in the U.S.S.R., and (3) the casting of Riband steel proposed by United States Steel Corp. But none of them appeared fully reliable. The fourth problem was that of start-up. After blowing in, production by the large blast furnace, with a daily production capacity of $10000 \mathrm{t}$, would increase very rapidly. It was thought impossible to hold its daily production below the level of 3000 or $4000 \mathrm{t}$ after a month. The continuous casting equipment therefore had to be operated at a corresponding rapid rate. However, much uneasiness was felt as to its operational aspects, such as initial breakdowns, lack of training and experience on the part of operators, difficulty in absorbing operational irregularities resulting from starting the blast furnaces, basic oxygen furnaces and continuous casting equipment at the same time, and so on.

The fifth problem was how to treat the hot metal supplied from the basic oxygen furnaces when the con- 
tinuous casting equipment became inoperable owing to temperature, refractory or other troubles. Because each furnace was to be designed to such a large capacity as $300 \mathrm{t}$, it seemed technically difficult to provide any effective measures. Even if possible, they would be limited in extent. Therefore, occurrence of such troubles in succession would inevitably result in a shut-down of the entire works.

The sixth problem related to the design of a slab handling system suited for the full continuous casting operation. We had no experience at all in this field. It involved many difficulties concerned with mass transporation, inspection of the surface condition and interior quality of slabs, their conditioning, guarantee of their properties, and transfer of steel from the basic oxygen furnaces to the continuous casting machines.

\section{(3) The Solutions Worked Out}

All the knowledge and expertise that we possessed was concentrated in order to covert our " technical dreams " into reality by solving the above-mentioned problems inherent in the full continuous casting process in the shortest possible period of time. But the study on a plan to provide a primary mill side by side with the continuous casting equipment was continued until final conclusions were reached. The solutions found by us were as follows:

With regard to the first problem about productivity, possibilities of high-speed casting, multi-strand casting, and reduction in preparation and maintenance time were chiefly studied, so as to introduce all necessary related techniques in the design of the equipment. As a result, we came to believe that we would be able to achieve a monthly production of $100000 \mathrm{t}$ or more per caster. This meant that a conventional-type primary mill corresponding in scale to the two blast furnaces joint production of $650000-\mathrm{t} /$ pig monthly could be supplanted by five or six continuous casters.

To solve the second problem of process limitations, actual operating conditions of mills distributed throughout all works of the company were carefully examined. Then it was found that this problem would not constitute any serious obstacle, and besides most of the technical problems unsolved at that time were expected to be solved sooner or later. The fact that there were a plurality of steelworks that had primary mills operated as the center of their production activities, and that distribution of steel to the individual mills and other production control procedures were systemized was much conductive to the finding of the solution to this problem.

The third problem was in the manufacture of continuous cast slabs comparable in quality to the conventinal rimmed steel. Considering its importance, actual operating conditions of similar plants and response of users in the Soviet Union, United States and some European countries were investigated several times. Based on the results of such investigations, test casting was repeated on the existing casters and the products were furnished to some users for trial use. It was established that said object would be attained by the use of Riband steel developed by United States
Steel Corp., and by making up for its disadvantages by casting aluminum-killed steel.

As a solution to the fourth problem of catching up with the rapid start-up of the blast furnace, it was decided to provide a pig machine on the blast furnace side, and a pouring line to make ingots and a mold yard of minimum size on the steelmaking side. They were to be removed when the continuous casters had reached their full operation levels. Test rolling on the continuous hot-strip mill, which is the subsequent process to continuous casting, was started half a year earlier, while operational training on the slab handling facilities was repeated using cold slabs, in order to prepare for the simultaneous start of the blast furnace, basic oxygen converters and continuous casting machines.

For the fifth problem of how to treat molten steel in case of emergency, the equipment and operating method to send it back to the basic oxygen furnace for re-treating were developed. Also, said pouring line for ingot-making was to be used for this purpose, as a tentative measure.

As to the sixth problem of slab handling, unmanned slab handling equipment and an on-line trucking system, extensively adopting sensors and computer techniques, were developed. Also, various effective combinations of table rollers, skids and other equipment were contrived to increase the effectiveness of the online slab handling.

After thus examining its possibility by the use of accumulated technical knowledge and the execution of many casting tests, we eventually decided to adopt the full continuous casting method. It was about half a year after the start of our planning work that we reached this conclusion. Still we continued various studies and preparations until the start of operation so that nothing would be omitted.

\section{Operational Results}

\section{The Sea-berth}

Four months after the start of operation, a $280000 \mathrm{t}$ deadweight ore carrier was moored along the seaberth. Then, $100000 \mathrm{t}$ of ore were unloaded in $24 \mathrm{hr}$ by use of two unloaders, each having a capacity of $2500 \mathrm{t} / \mathrm{hr}$. Besides, the downtime time due to bad weather was less than $10 \%$ even in the worst month, proving the correctness of our preliminary investigations.

\section{Realization of Full Continuous Casting}

During the first six months after the start of their operation in April 1972, the continuous casting machines were confronted with various start-up difficulties. But after that we approached our goal of introducing the full continuous casting method into an integrated steelworks with a 4000000 -annual-ton production capacity in a very satisfactory manner. About a year after the first casting had been made, the need to make ingots no longer existed, and the full continuous casting operation system was established as aimed. (Fig. 7)

Already, production yields have been improved by 


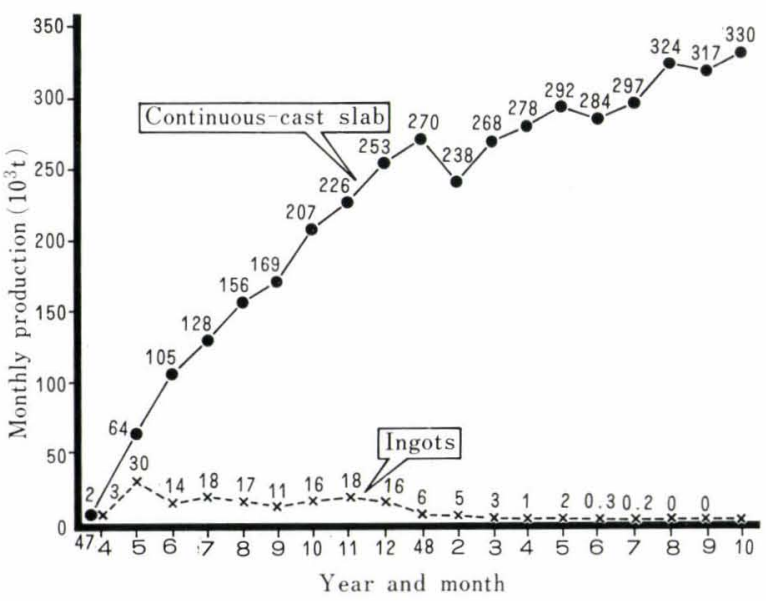

Fig. 7. Progress of continuous-caster monthly production

5 to $10 \%$, and the amount of energy saved also has reached the desired level. With regard to labor saving, we have come very near to succeeding in the development of a fully remote-controlled casting technique (Photo. 5). Remarkable improvements have been achieved in the operators' working environments, too.

In addition, such high-quality steels as for tin-plate, deep-drawing quality cold-rolled sheets, high-grade line pipe and heavy plates became available earlier than had been originally expected. These items made of continuous-cast steels have been smoothly accepted by the users. The monthly production achieved by a single caster has reached $176000 \mathrm{t}$, or $330000 \mathrm{t}$ by three casters, and further increase is expected in the future.

\section{Performance of the Total Computer System}

From the start, all the operations in the Works have been controlled by the total computer system. To show the reliability of the system, the operating rate of the on-line real time computer that controls the entire works, which had been $97 \%$ at the start of operation, exceeded $99 \%$ within a year, and hit the first-stage target of $99.5 \%$ without difficulty. Then in the second year, the second-stage target of $99.7 \%$ was realized. (Fig. 8)

When the computer malfunctioned, a quick-responding back-up system operated smoothly to avoid discontinuance of operations. However, efficiency dropped to 60 to $70 \%$, since all the works had to be performed manually. Therefore, additional efforts were directed to the improvement of the system's reliability. As a result, it became possible to transfer accurate information, manintain high-precision control, and perform smooth operation of equipment. Also, the first phase of labor saving, intended for the two blast-furnace stage, was accomplished by reducing manpower by about 1000 .

\section{Conclusions}

In the foregoing, it was described how Oita Works came into existence, as a modern steelworks to make full use of the accumulated experience and knowledge and to meet the ever-changing demands from the steel

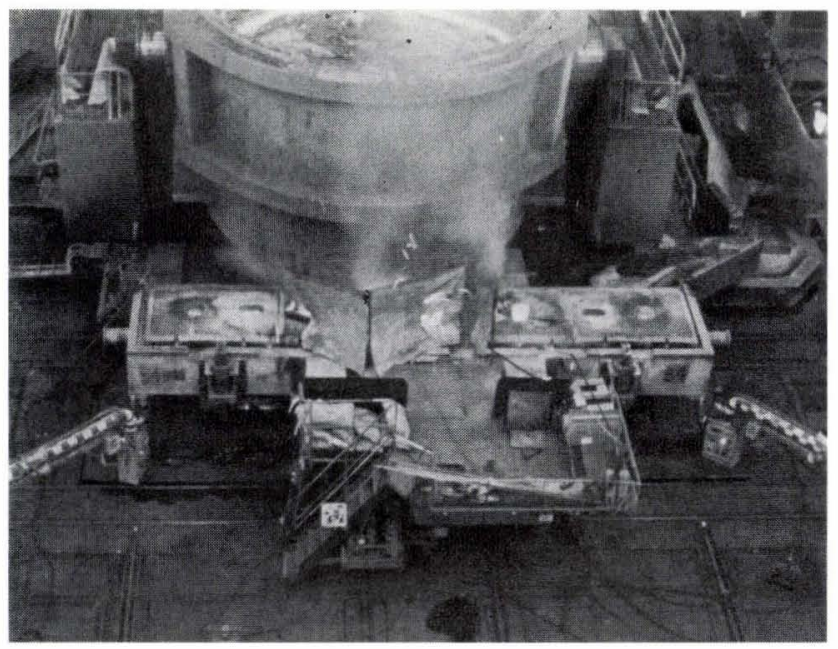

Photo. 5. Unmanned control of the continuous casting machines

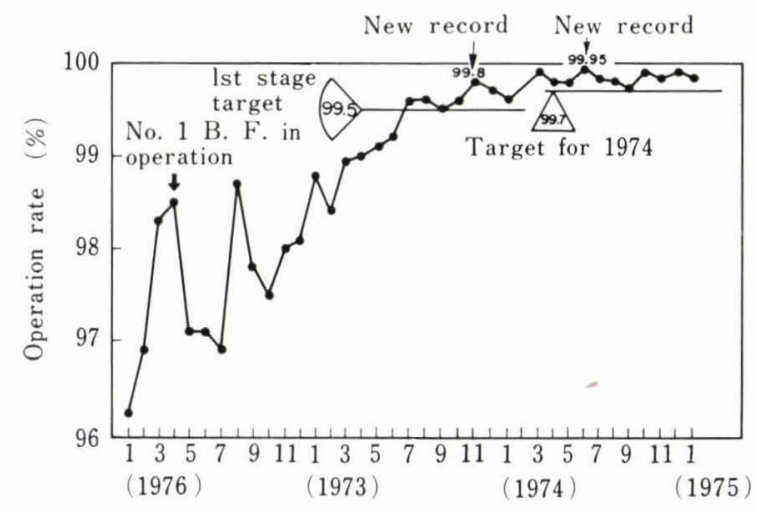

Fig. 8. Progress of the Oita Works total on-line system's operation rates

consuming sectors. This project may be called " a Challenge to New Techniques," since it involved the following important steps:

1) Setup of the course for the future techniques

2) Check-up of technical possibilities of realizing such course, and making necessary decisions

3) Solution of problems in equipment and techniques for the realization of the object

4) Demonstration of operation technology and techniques.

Especially, the check-up and decision-making on technical possibilities will differ greatly from person to person. When a number of techniques covering extensive areas of projected work includes many unsolved problems, as in this case, we tend to seek solutions on the safer side. But we succeeded in avoiding such a wait-and-see attitude by collecting as much data as were then available and making as many tests and investigations as possible, which enabled us to make definite decisions.

At Oita Works, construction of the two-blast-furnace stage is in progress. All of the planned objectives, however, have not been achieved yet. So further efforts for more improvements in various technical fields are required. 
During the past two decades, the Japanese steel industry kept on developing, cultivating its technical potentiality and productivity. However, it is now facing an unprecedentedly difficult situation. Whether or not this critical situation can be successfully over- come will decide the fate of the Japanese steel industry. Therefore, before concluding this paper, the author sincerely hopes that its leaders and all other people working in the industry will lend every effort to tide over the difficulties of this period. 